\title{
Covid-19: Oral manifestations, impact and lessons for the future
}

\author{
Dr Bashu Dev Pant \\ Assistant Professor, Department of Orthodontics, \\ Peoples Dental College and Hospital, Kathmandu, Nepal
}

Corresponding author: Dr. Bashu Dev Pant, Email: pantbasudev50@yahoo.com

\section{ABSTRACT}

The coronavirus disease 2019 (COVID-19) is a respiratory infectious disease caused by severe acute respiratory syndrome coronavirus-2 (SARS-CoV-2). The SARS-CoV-2 is mainly transmitted through respiratory droplets and close contact. Most of the infected people present with fever, cough and difficulty in breathing; some develop severe pneumonia, renal and multi-organ failure and some may remain asymptomatic. It has halted the economy and many people have lost their job or reduce their income significantly across the globe. Orthodontic patients coming for the treatment are under fear of contracting disease therefore number of patients are decreased and orthodontic practitioners are also afraid of doing treatment because of fear of contracting disease so; it has direct negative effect on the economy of orthodontic practitioners. Large number of orthodontic patients are in need of orthodontic return-visits, all patients who come for orthodontic visits should be performed with preventive measures to control transmission COVID-19.

KEYWORDS: Coronavirus, COVID-19, Impact, Oral manifestations.

\section{INTRODUCTION}

Since its emergence in Wuhan, China in December 2019,' COVID-19 spreads rapidly all over the world and now became a global pandemic. The World Health Organization (WHO) declared a pandemic in March 2020. The United State and European countries are more sufferer than Asian countries and mortality rate also more in western countries.

It is a single-stranded RNA virus can be directly transmitted through respiratory droplets of an infected person who comes in contact of others. ${ }^{2}$ It is also transmitted by fomites through the touching of contaminated materials or aerosolization transmission in a confined space. ${ }^{3,4}$

Contact transmission of the virus can also be attributed to the abundance of ACE2 receptors found in the oral, nasal mucosa and nasopharynx. ${ }^{5}$ Due to which healthcare workers especially dental practitioners puts at higher risk.
In orthodontic treatment it involves a large population who need to routine follow up visits, it was largely affected by COVID-19 pandemic and closure of the dental clinics and hospitals. In many areas have gradually resuming regular services but orthodontic patients are still under high risks of infection. This is due to patient may be asymptomatic carriers of infection or in the incubation period which may cause the cross-infection between orthodontic practitioners and patients. Also there is close proximity to patients and the generation of droplets and aerosols in the saliva and blood during treatment further increase the risks of transmission. ${ }^{6}$

With ease of lockdown quantitatively there is increased need and complexity of orthodontic treatment so we need to resume orthodontic services safely and effectively with necessary personal protective equipment (PPE) and proper infection control protocol.

\section{ORAL MANIFESTATIONS}

Covid-19 pandemic possesses great threat to global health. Common signs and symptoms at onset of illness 
are fever, headache, dry cough, sore throat, fatigue, myalgia, dyspnea, anorexia and pneumonia. 'However some patients presented with atypical symptoms, such as nausea and diarrhea. Oral manifestations of this infection are:

Salivary Gland Infection: In majority of patients COVID-19 infection was detected in saliva and it may cause infection of salivary glands, ${ }^{7}$ which increases the availability of virus in the oral cavity and its uptake by the epithelial cells in the oral mucosa.

Taste Abnormalities: Loss of taste and smell was one of the symptoms of COVID-19 as described by a study in which 20 patients had at least one taste or smell disorder and 11 (18.6\%) had both out of 59 COVID-19 patients who were interviewed (33.9\%). ${ }^{8}$ Taste and smell disorder in this study was due to interaction of COVID-19 with angiotensin converting enzyme 2 (ACE2) receptor, to facilitate its penetration into the cell, and this receptor is widely present on the epithelial cells of oral mucosa and the brain. ACE2 was found to be higher in tongue, where the taste buds are most abundant. ${ }^{9}$

Dry Mouth: According to a study conducted in Israel, out of 140 patients seventy-two patients reported dry mouth and there was a strong association with burning mouth and taste change. ${ }^{10}$

Oral ulceration and blistering: Oral ulceration or blistering was found in patients with confirmed or suspected COVID- 19."

\section{IMPACT ON ORTHODONTIC PRACTICE}

After the sudden announcement of lockdown all dental clinic and hospitals were closed for more than 3 months which causes negative impact on revenue and earnings. When nation-wise lockdown was eased orthodontists were instructed to only provide emergency treatments for the time being and we enter in a recovery period but uncertainty remains for long term provision of orthodontics.

COVID-19 causes drastic change in the work environment for orthodontist and current economic losses increase in expense and lack of resources to fulfill them. Despite being shut, clinics have to bear salaries to the staff, rent, bills of water, electricity, internet and water. ${ }^{12}$ It has more negative effect on the newer orthodontists who has opened clinic recently and has to pay loan of the bank or orthodontists visiting to the general dental clinic.
It has halted the economy and many people have lost their job or reduce their income significantly across the globe. Orthodontic patients coming for the treatment are under fear of contracting disease therefore number of new and old patients are decreased and orthodontic practitioners are also afraid of doing treatment because of fear of contracting disease so; it has direct negative effect on the economy of orthodontic practitioners. Sudden announcement of lockdown has resulted in missed appointments might have led to breakage of the brackets, bands and appliances which can cause increased duration of treatment and cost, thereafter.

\section{LESSONS FOR THE FUTURE}

Worldwide countries are responding differently to this COVID -19 pandemic. A delay in testing and response has been found in Nepal as well as many other countries, which can cause risk of transmission and overburdening of the health facility. The health care community and government has golden opportunity to learn from the current experience of this pandemic to make plan for the future design of the optimal health care system that enhance quality care, accessibility and minimum burden of cost on the patient.

Social distancing and improving hygienic practices are the public health interventions and these interventions will be effective in delaying the widespread community transmission, reducing peak incidence and its impact on public services..$^{13}$ Testing, contact tracing, isolation of infected patient and self isolation of contacts is critical in reducing the number of new cases. ${ }^{14}$

Now it is very difficult to predict the future of orthodontics after COVID-19. As patients initially focus only on emergency treatment or the treatment that really matters to them and orthodontic treatment is concerned with aesthetics and function so after normalization of situation, number of patients coming for treatment will be increased so there is no point in being pessimistic about the future.

Telemedicine has been emerging as a necessary means to sustain the health system during the pandemic, policymakers has to make a plan to appreciate fully how to capitalize on this potential in normal times. In addition, rapidly developing scientific and technological advances in robotics, sensors, artificial intelligence, genomics and nanotechnology provide a basic foundation in health care system for delivering the 
right care to the right patient at the right time; also it minimizes inappropriate treatment, side effects and inefficiencies. The telemedicine community must look beyond the traditional role of telemedicine as a connectivity tool only. ${ }^{15}$

Smart and improved clinical working may have to be practiced to mitigate COVID 19 transmission in the future. Digital didactic and online learning can be performed for months. ${ }^{16}$ Teledentistry, and in particular teleorthodontics, needs to be implemented.

There are various guidelines to form contingency plans for orthodontic practices and according to these guidelines clinics need to be renovate, adding to the rising expenditures in the practice. ${ }^{17}$ Expenditure includes newer personal protective equipment (PPE) such as N95 masks, face shields, head and shoe covers, sanitizers, disinfectants and HEPA filter which might be imperative for non stressful management and retain the confidence of the patients.

\section{CONCLUSION}

COVID-19 and associated lockdown policies has profound negative effect on orthodontic practices. Until the development of vaccine and its effective distribution orthodontic practitioners have to adapt practices to protect themselves, patients and public.

\section{OJN}

\section{REFERENCES}

1. Wang D, Hu B, Hu C et al. Clinical Characteristics of 138 Hospitalized Patients With 2019 Novel Coronavirus-Infected Pneumonia in Wuhan, China. JAMA 2020; 323: 1061-1069.

2. Paul GA. Coronavirus COVID-19 (SARS-CoV-2). Johns Hopkins ABX Guide. United States: The Johns Hopkins University; 2020. Available from: http://www hopkinsguides.com/hopkins/view/johns_hopkins_abx_guide/540747/all/ coronavirus_covid_19_sars_cov_2_.

3. Rodriguez-Morales AJ, MacGregor K, Kanagarajah S, Patel D, Schlagenhauf P. Going global-travel and the 2019 novel coronavirus. Travel Med Infect Dis 2020;33:101578.

4. Wax RS, Christian MD. Practical recommendations for critical care and anesthesiology teams caring for novel coronavirus (2019-nCoV) patients. Can J Anaesth 2020;67:568-76.

5. Hamming I, Timens W, Bulthuis ML, Lely AT, Navis GJ, van Goor H. Tissue distribution of ACE2 protein, the functional receptor for SARS coronavirus. A first step in understanding SARS pathogenesis. J Pathol 2004;203:631-7.

6. Guo Y, Jing Y, Wang Y, To A,Du S, Wang L and Bai D. Control of SARS-CoV-2 transmission in orthodontic practice. Am J Orthod Dentofacial Orthop 2020. doi: 10.1016/j.ajodo.2020.05.006

7. Kotfis, K.; Skonieczna-Żydecka, K. COVID-19: Gastrointestinal symptoms and potential sources of $2019 \mathrm{nCoV}$ transmission. Anaesthesiol. Intensive Ther. 2020, 52, doi:10.5114/ait.2020.93867.

8. Giacomelli, A.; Pezzati, L.; Conti, F.; Bernacchia, D.; Siano, M.; Oreni, L.; Rusconi, S.; Gervasoni, C.; Ridolfo, A.L.; Rizzardini, G.; et al. Selfreported olfactory and taste disorders in in patients with severe acute respiratory coronavirus 2 infection: A cross-sectional study. Clin. Infect. Dis. 2020, doi:10.1093/cid/ciaa330.

9. Xu, H.; Zhong, L.; Deng, J.; Peng, J.; Dan, H.; Zeng, X.; Li, T.; Chen, Q. High expression of ACE2 receptor of 2019-nCoV on the epithelial cells of oral mucosa. Int. J. Oral Sci. 2020, 12, 1-5.

10. Biadsee A, Biadsee A, Kassem F, Dagan O, Masarwa S and Ormianer Z. Olfactory and Oral Manifestations of COVID-19: Sex-Related Symptoms-A Potential Pathway to Early Diagnosis. SAGE public health emergency collection 2020. PMC7298562.

11. Sinadinos A and Shelswell J. Oral ulceration and blistering in patients with COVID-19. Evidence-Based Dentistry (2020) 21, 49

12. Kochhar AS, Singh G. Financial Aspect of COVID-19 on Orthodontic Practice in India. Journal of Indian Orthodontic Society. 2020;54(3) 276-277.

13. Wilder SmithA, Chiew CJ, Lee VJ. Can we contain the COVID 19 outbreak with the same measures as for SARS? The Lancet Infectious diseases. 2020. doi: 10.1016/s1473 3099 (20) 301298.

14. Salathe M, Althaus CL, Neher R, Stringhini S, Hodcroft E, Fellay J, et al. COVID 19 epidemic in Switzerland: On the importance of testing, contact tracing and isolation. Swiss Med Wkly 2020;150:w20225.

15. Bashshur R, Doarn CR, Frenk JM, Kvedar JC and Woolliscroft JO. Telemedicine and the COVID-19 Pandemic, Lessons for the Future. Telemedicine and e-Health.2020;26(5). https://doi.org/10.1089/tmj.2020.29040.rb

16. Khanna RC, Cicinelli MV, Gilbert SS, Honavar SG, Murthy GS. COVID-19 pandemic: Lessons learned and future directions. Indian J Ophthalmol 2020;68:703-10

17. Suri S, Vandersluis YR, Kochhar AS, Bhasin R, Abdallah M. Clinical orthodontic management during the COVID-19 pandemic [published online Apr 27, 2020]. Angle Orthod. doi:10.2319/033120-236.1. 